\title{
Impact of Discrimination on Health among Adolescent Immigrant Minorities in Europe: The Role of Perceived Discrimination by Police and Security Personnel
}

\author{
Mathias Kauff, Ralf Wölfer, \& Miles Hewstone
}

For Journal of Social Issues "What Social Science Research Says About Police Violence Against Racial and Ethnic Minorities: Understanding the Antecedents and Consequences."

\section{Author Note}

The CILS4EU research project was funded by the NORFACE ERA NET Plus Migration in Europe-programme. Correspondence concerning this article should be addressed to Mathias Kauff, Fernuniversität in Hagen, Universitätsstr. 33, 58084 Hagen, Germany. Email: mathias.kauff@fernuni-hagen.de

\section{Authors' Bios}

MATHIAS KAUFF is a Postdoctoral Researcher at the FernUniversität Hagen, Germany. His research interests include intergroup relations, social identity, prejudice and discrimination, attitudes towards diversity, and intergroup contact.

RALF WÖLFER is a Postdoctoral Researcher in the Centre for the Study of Intergroup Conflict at the University of Oxford. His main research objective is to examine how social relationships affect human behavior and vice versa with a specific focus on aggressive behavior. MILES HEWSTONE is Professor of Social Psychology and Public Policy and Director of the Centre for the Study of Intergroup Conflict at the University of Oxford. His main research topic is intergroup relations and the reduction of intergroup conflict, especially via intergroup contact. 


\begin{abstract}
Previous research has shown negative effects of discrimination on ethnic minority members' health and well-being. In this study, we examined cross-sectional and longitudinal effects of discrimination by members of the police and security personnel over and above other types of discrimination and ethnic victimization on the health of immigrant minority students from three different European countries ( $N=4,334$ immigrant students from 580 ethnically mixed school classes in Germany, the Netherlands, and Sweden). Results indicate that perceptions of ethnic victimization in the school (measured via social network data) as well as three types of discrimination outside school (discrimination in clubs, public transportation as well as by the police and private security) are associated with current and future negative health outcomes (i.e., psychosomatic problems) in immigrant minority students. Among the different types of discrimination, discrimination by the police and private security personnel was most common and had the most negative effect on immigrant minority students' health. Practical and political implications of our findings as well as differences in discrimination and violence by the police between the US and Europe are discussed.
\end{abstract}

Keywords: discrimination, immigrant minorities, health, police 


\section{Impact of Discrimination on Health among Adolescent Immigrant Minorities in Europe: The Role of Perceived Discrimination by Police and Security Personnel}

Prior research has shown that experiences of discrimination negatively impact health and well-being in members of minority groups (e.g., Schmitt, Branscombe, Postmes, \& Garcia, 2014; Pascoe \& Smart Richman, 2009). In the present research, we focus on the effects of one particular form of discrimination against members of immigrant minority groups, namely discrimination by members of the police and security firms. More precisely, we examine the specific influence of discrimination of immigrant minority members by members of the police and security firms on health problems over and above other types of discrimination and ethnic victimization. We hereby focus on immigrants in their adolescent years because adolescents have been shown to be especially distrustful of the police (e.g., Hurst, 2007; Schuck, 2013) and vulnerable to health problems as a consequence of discrimination (Brody et al., 2006; Fisher, Wallace, \& Fenton, 2000).

In contrast to most other articles in this issue, we do not directly study antecedents and consequences of blatant aggressive behaviors by the police (e.g., Byrant-Davis, Adams, Alejandre, \& Gray, 2017; Charbonneau, Spencer, \& Glaser, 2017; Kahn \& Davies, 2017; Scott, Correll, Sadler, \& Ma., 2017). This is due to the fact that our research was conducted amongst immigrant minority members in three European countries (i.e., Germany, the Netherlands, and Sweden) ${ }^{1}$. For cultural and legal reasons examples of blatant police violence and shootings are less frequent in Europe than in the USA. However, ethnic discrimination, representing a more subtle form of aggression, is common place among police officers in Europe and can also have serious negative consequences for ethnic and immigrant minority group members (e.g., European Union Agency for Fundamental Rights, 2010). With regard to behavior of employees of private security firms, less evidence is available and because they operate largely outside of public scrutiny they may discriminate with impunity. 


\section{Ethnic Discrimination and Health}

A plethora of studies has examined the relationship between (perceived) ethnic discrimination and health outcomes or well-being. In a recent meta-analytic study, Schmitt et al. (2014) present evidence based on data from 328 correlational and 54 experimental data sets. They conclude that "perceiving the self as a target of discrimination harms psychological well-being" (Schmitt et al., 2014, p. 14). Moreover, their results indicate that the negative relationship between perceptions of discrimination and well-being exists across different social contexts, targets of discrimination, and for measures of well-being (for comparable meta-analytic evidence focusing specifically on ethnic discrimination see Conklin, 2011). Schmitt et al. (2014) also found that consequences of discrimination are more negative for members of disadvantaged groups than for members of advantaged groups. Other studies indicate that perceptions of discrimination are generally more common among minority group members. Coker et al. (2009) showed that $5^{\text {th }}$ graders from ethnic minority groups in the US experience more ethnic discrimination than students from the White majority group and that perceptions of discrimination worsen mental health (see also Mewes, Asbrock, \& Laskawi, 2015, for results for Turkish immigrants in Germany; Verkuyten \& Nekuee, 1999, for results for Iranian refugees in the Netherlands). Furthermore, several studies indicate that perceptions of ethnic discrimination lead to an increase of psychiatric problems (Berg et al., 2011; Borders \& Liang, 2011; Gee, Ryan, Laflamme, \& Holt, 2006). In a similar vein, Sue et al. (2007) have argued that pervasive microaggressions, that is indirect, small, and unintended indignities directed towards ethnic minorities (such as presuming that ethnic minorities are dangerous or criminal) negatively influence their wellbeing.

However, perceptions of ethnic discrimination do not only influence mental health outcomes but also physical health outcomes (e.g., headaches and stomach aches; Huynh \& Fuligni, 2010; Landrine \& Klonoff, 1996). Jasinskaja-Lahti, Liebkind, Jaakkola, and Reuter (2006), for example, surveyed more than 3,500 individuals from different immigrant groups in Finland 
and showed that perceived ethnic discrimination not only influenced mental health outcomes (i.e., psychological distress) but also ratings of general health. Similarly, Pascoe and Smart Richman (2009) presented meta-analytic evidence based on 134 independent samples showing that perceived discrimination had a comparable effect on both mental and physical health.

What drives the negative effect of perceived discrimination on health and well-being? Pascoe and Smart Richman (2009) studied two different processes underlying the relationship between discrimination and health. First, discrimination can be regarded as a stressor (Major, Quinton, \& McCoy, 2002), which can induce physiological stress responses (e.g., Brondolo et al., 2008). In a similar vein, Carter (2007) argues that perceptions of racist and discriminatory behavior can under certain conditions even lead to post-traumatic stress reactions. Moreover, chronic confrontation with a stressor can reduce health protective resources and increase vulnerability to illness (Gee, Spencer, Chen, \& Takeuchi, 2007). Second, experiences of discrimination can reduce self-control (Inzlicht, McKay, \& Aronson, 2006) and, hence, increase dysfunctional and unhealthy behavior (e.g., Bennett, Wolin, Robinson, Fowler, \& Edwards, 2005; Landrine \& Klonoff, 1996). In fact, both processes were found to be significant mediators in Pascoe and Smart Richman's (2009) meta-analysis (see also Okazaki, 2009). Although some scholars argue that structural or institutional forms of unequal treatment are especially critical to the health of members of ethnic minority groups (Viruell-Fuentes, Miranda, \& Abdulrahim, 2012; Williams \& Mohammed, 2013), most studies in this field neither specifically address structural or institutional discrimination, nor differentiate between institutional and non-institutional discrimination. An exception is the study by Verkuyten (2008) that showed that structural discrimination (among others, discrimination by the police) has a direct negative effect on life satisfaction of Turkish immigrants in the Netherlands.

In the present paper, we focus on health-related consequences of discrimination against immigrant minorities by the police and security personnel. Moreover, we draw on a sample of adolescent immigrants for two reasons. First, and in line with the aforementioned study by Coker 
et al. (2009), other studies indicate that adolescent immigrants are especially prone to react to discrimination with health problems such as depressive symptoms (Brody et al., 2006) or decreased self-esteem (Greene, Way, \& Pahl, 2006). Second, experiences of discrimination and related health- and behavioral problems during the formative years of adolescence can have especially negative consequences such as poor academic performance, school dropout, and unemployment during young adulthood (e.g, Bergman \& Magnusson, 1997; Cairns, Cairns, \& Neckerman, 1989, Steele \& Aronson, 1995), which themselves have long-term consequences for minority members specifically, for intergroup relations in general, and for society at large (e.g., failure to exploit the potential of human capital, both in terms of developing individuals' potential, and ensuring that the most able people are placed in the most suitable jobs).

\section{Ethnic and immigrant minority members and the police in the US and Europe}

Majority-minority relations have both commonalities and differences across national, cultural and societal contexts. Since the second half of the last century, Europe has experienced continuous waves of immigration from former colonies, so-called "guest workers", or war refugees. Many of these immigrants have a low-status position within the immigration country and not only lack integration (e.g., in schools or the labor market), but are also specific targets of prejudice, discrimination, and violence (see for example Zick, Pettigrew, \& Wagner, 2008). The US also has a long history of immigration with similar problems of integrating ethnic and immigrant minority groups and the consequential potential for intergroup conflict (MIPEX, 2015). In contrast to Europe, however, conflicts in the US can sometimes culminate in armed violence. Due to legal regulations, access to and usage of weapons is, even before adulthood, a widespread phenomenon in the US (e.g., Dijkstra et al., 2010; Sorenson \& Vittes, 2005) leading to a serious threat, particularly for individuals who are targets of discrimination. Weapon carrying, however, is less common in Europe, which inevitably leads to less use of weapons among both citizens as well as police officers, who are, in contrast to officers in the US, rarely confronted by 
armed offenders. Also, in parts of Europe (e.g., the UK and to some extent France), police officers are not even routinely equipped with guns. Moreover, the legal justification for shooting suspects differs between the US and Europe: Warning shots are prohibited in most US states and only eight states instruct officers to give verbal warnings before shooting. In some European countries (i.e., Finland and Norway), however, officers are required to ask for supervisors' permission before shooting suspects (Amnesty International USA, 2015; Hirschfield, 2015a).

Besides these legal preconditions, Hirschfield (2015b) argues that police killings in the US are also "rooted in American-style individualism that emphasizes self-reliance and such corollary values as decentralized government (i.e., self-rule) and individual moral responsibility". As one consequence a widespread gun culture and related problems arose in the US (see above). More importantly, however, beliefs in individual moral responsibility make US police forces especially sensitive to threats and supportive of officers who do not hesitate to aggressively approach suspects. Additionally, according to Hirschfield (2015b), widespread societal racism in the US accounts for the large number of shootings of ethnic minority members. Moreover, Haberfeld (2013) argues that training of police officers in the US is too short and does not adequately address issues related to use of lethal force. In fact, the average training of police officers in the US is fifteen weeks while in the Netherlands, Norway, Germany, and Finland police officers attend national academies for years (Haberfeld, 2013; Hirschfield, 2015a).

Due to the aforementioned reasons, police shootings in general and police shootings of ethnic minorities specifically are less common in Europe than in the US (Lartey, 2015; for the analysis of one still-rare example of a police shooting in Europe see Reicher \& Stott, 2011). Nonetheless, despite differences in the use of extreme forms of violence and the consequential fatal health risk for discriminated ethnic and immigrant minority groups in the US, it is important to note that even being a victim of unarmed violence and discrimination can result in serious health problems (Schmitt et. al, 2014; Pascoe \& Smart Richman, 2009; Verkuyten, 2008). 
Unfortunately, police discrimination seems to be commonplace in Europe. Members of ethnic and immigrant minority groups regularly report experiences of police discrimination although minority members typically underestimate the extent to which they are discriminated against (Barreto \& Ellemers, 2015). Results from the European Union Minorities and Discrimination Survey (EU-MIDIS) that surveyed 23,500 immigrant and ethnic minority members in 22 European Union member states show that immigrants and ethnic minorities reported significantly more often being stopped by the police than did majority members. Moreover, immigrant and ethnic minority members were more likely to be asked for their identification by the police (European Union Agency for Fundamental Rights, 2010). Likewise, German police officers are legally justified in verifying the identity of individuals without reasonable suspicion which, according to ethnic minority pressure groups and Amnesty International, leads to so-called racial profiling (Amnesty International, 2014; Bundespolizeigesetz, 1994; KOP Berlin, 2014). Moreover, quantitative and qualitative surveys in the German context indicate that a small but substantial number of police officers hold xenophobic attitudes (Dollase, 2000; Leenen, 2005; Mletzko \& Weins, 1999). These results suggest that ethnic discrimination by the police may be a relatively common phenomenon in European countries. Racial profiling (Gabbidon, 2003) as well as other types of discrimination by private security personnel (such as unjustified controls or harassment at airports or train stations) are also common (e.g., Bonino, 2015).

There are four main reasons why we consider it important to specifically address consequences of discrimination by the police. First, from a moral stance, police and law enforcement in democratic societies are public services and should therefore equally address the needs and rights of majority and minority members. Second, behavior of police forces builds the basis for reporting criminal offenses. It is likely that due to perceived discrimination immigrant and ethnic minority members lose trust in the police. In fact, data from the EU-MIDIS show that immigrant and ethnic minority members' perceptions of discrimination by the police are 
associated with reduced trust in the police (Van Craen, 2013; Van Craen \& Skogan, 2015). As one possible consequence immigrant and ethnic minority members refrain from reporting crimes (European Union Agency for Fundamental Rights, 2010). Third, given the role of police forces as state representatives, perceived discrimination of immigrant and ethnic minority members by the police is likely to be generalized to general feelings of rejection from society as a whole.

Therefore, we argue that the negative effects of police discrimination on victims' health and wellbeing should be especially strong compared to other types of discrimination. Fourth, confronting discrimination, for example by expressing discontent towards the person(s) responsible, can have positive intrapersonal consequences for the confronting person (Barreto \& Ellemers, 2015). Hyers (2007), for example, showed that women confronting prejudice were more satisfied with their responses to prejudice than non-confronters and felt more closure. However, confronting discrimination also has (mostly social) costs (for an overview see Kaiser \& Major, 2006). For example, people expressing their unease with prejudice or discrimination are often seen as oversensitive by others (e.g., Dodd, Giuliano, Boutell, \& Moran, 2001). Due to the constitutionally legitimized power imbalance between members of the police and citizens it is extremely difficult to confront police discrimination and obtain the putative intrapersonal benefits of such challenges. Moreover, if possible, confrontation goes along with enormous (social) costs: Complaining about police discrimination is especially likely to lead to a blaming of the victim because it threatens observers' beliefs in a just world (Kaiser, Dyrenforth, \& Hagiwara, 2006). Furthermore, it is likely that assertively expressed discontent with a behavior carried out by police officers is interpreted as a form of obstructing a member of the police in the course of his or her duty and sanctioned accordingly.

Taken together, police discrimination is likely to constrain such a course of action with a consequent perceived lack of control over the situation. Uncontrollable stressors (such as specific types of discrimination) have been shown to have particularly negative effects on individuals' health (Carter, 2007; Seligman, 1975; Williams \& Mohammed, 2009). Therefore, repeated 
experiences of discrimination by the police should be an especially powerful predictor of health problems.

While we cannot draw on comparable data with regard to discrimination by security personnel, we expect that similar processes operate, not least because private security firms employ many former members of the police (White, 2011). Moreover, such firms operate largely out of the public limelight, unlike police, with the risk that discrimination is uncontrolled and possibly greater.

It is important to note that, although we focus on discrimination by the police and private security personnel, we do not rule out that other types of discrimination studied in the present research also relate to negative health outcomes. In fact, Pascoe and Smart Richman (2009) showed that a number of different types of discrimination are associated with lower health. However, based on the existing literature, it is plausible to assume that police discrimination has, in comparison with other types of discrimination, a particularly detrimental effect on minority members' health above and beyond other types of discrimination.

\section{Overview of the Present Research}

This study examined the relationship between perceptions of discrimination and health outcomes in immigrant minority students in Europe. We focus on young members of immigrant minority groups because adolescents and minority group members have been shown to be specifically vulnerable to negative health effects of discrimination (Brody et al., 2006; Schmitt et al., 2014). Based on previous literature that indicates a negative effect of perceived ethnic discrimination on health outcomes (Benner \& Kim, 2009, Mewes et al., 2015; Seaton, Caldwell, Sellers \& Jackson, 2010), we expected a general effect of discrimination on immigrant minority school students' health problems, which is likely to be specifically harmful when the source of that discrimination is the police or private security personnel. Moreover, we assumed that police and private security discrimination has an influence on health problems over and above other 
types of discrimination. Because research on the effects of discrimination by the police and members of private security firms is scarce, the latter assumption should be regarded as an exploratory hypothesis.

\section{Method}

\section{Sample}

Participants were part of the "Children of Immigrants Longitudinal Survey in Four European Countries" (CILS4EU; Kalter et al., 2014, 2015). The data analyzed in this paper include the first two waves of this ongoing international collaboration between England, Germany, the Netherlands, and Sweden. At wave 1,14-year-old students were recruited and followed-up approximately one year later at wave 2. A school-based sample selection design was applied by considering all eligible schools in each country. Schools were selected randomly from different categories (i.e., school types, regions, immigrant proportion) in order to draw a sample that (a) is representative of all school types and regions in each country and (b) systematically oversampled ethnically diverse schools with a high proportion of immigrant minority groups (more information can be found in the technical report, CILS4EU, 2014). Participation rate was high for schools (84\%) and students (85\% within participating schools). From the four initial countries, England had to be excluded from the present analysis due to a technical problem during the assessment of the social network data. In the remaining three countries, classes with fewer than 15 students $(11 \%)$ were excluded in order to conduct meaningful analyses in reasonably large class-specific networks.

These exclusion criteria left a total of 12,988 students from 616 ethnically mixed school classes. At wave 1, completed data was available from $91 \%$ of students, who differed marginally from students with missing data regarding gender $(d=0.13)$ and age $(d=0.12)$; at wave 1 and 2 completed data was available from $71 \%$ of students, who similarly differed marginally from the rest regarding gender $(d=0.02)$ and age $(d=0.20)$. Thus attrition and drop out can be considered unsystematic. The final cross-sectional sample from wave 1 comprised 11,812 students $\left(M_{A G E}=\right.$ 
14.96 years; $51 \%$ girls) including 4,334 immigrant students from 580 school classes. The final longitudinal sample from waves 1 and 2 included 9,206 students $\left(M_{A G E}=15.98\right.$ years; $51 \%$ girls $)$ including 3,236 immigrant students from 540 school classes. Immigrant students were considered as minority members and used for testing our main research question. However, the overall sample was considered for calculating measures for ethnic victimization and diversity.

\section{Measures}

Data from both waves were collected in the regular school setting by the middle of the school years 2010/2011 and 2011/2012, respectively. With the help of trained test administrators, participants answered standardized questionnaires that primarily assessed migration-specific characteristics, core dimensions of integration, and social network data (detailed information is available in the respective codebooks: CILS4EU, 2014, 2015), from which we analyzed the measures described below.

Health problems. At waves 1 and 2, participants reported the frequency of health problems within the last six months on three items (common stem: "In the last six months, how often have you had [...]"; item-specific completion: "a headache?", "stomach ache?", "difficulties falling asleep?") using a five-point scale $(1=$ never to $5=$ every day $)$. The mean of these three items represented students' health problems at each respective wave with a reliability of Cronbach's $\alpha=$ .65 at wave 1 and .68 at wave 2 .

Ethnic victimization in school. We assessed network data in each school class using a peer nomination procedure (first five nominations in response to: "Who is sometimes mean to you?"). Subsequent network analysis elicited negative networks in all classes, which have been shown to be a valid measure of intergroup aggression (Wölfer \& Hewstone, 2015). Based on students' immigrant status, these negative network data allowed us to precisely measure the extent to which immigrant minority students reported being victimized by majority students, by determining the number of negative links from minority to majority students (e.g., network 
member \#2 to \#11 in Figure 1). The sum of nominated majority aggressors represents immigrant minority students' amount of perceived ethnic victimization in school.

\section{Insert Figure 1 about here}

Perceived discrimination. Participants reported the frequency of perceived discrimination on three items (common stem: "How often do you feel discriminated against or treated unfairly [...]"; item-specific completion: "in trains, buses, trams or the subway?", "in shops, stores, cafés, restaurants or nightclubs?", "by police or security guards?") using a fourpoint scale $(1=$ never to $4=$ always $)$. Single items were treated as separate predictors in order to compare the frequency and effects of different types of discrimination.

Control variables. In the cross-sectional analysis, we controlled for important sociodemographic variables, such as sex and age, as well as contextual variables, such as diversity (i.e., proportion of immigrant minority students in school class) and class size (i.e., total number of students in class). In the longitudinal analysis, we additionally controlled for previous health problems at wave 1 .

\section{Statistical Analyses}

The data from immigrant minority students were analyzed in two steps. First, we examined the frequency of ethnic victimization and different types of discrimination that minority students experience and, second, we compared the effects of these predictors. For the latter, we used multilevel modeling (Raudenbush \& Bryk, 2002) to adequately consider the nested data structure with students on Level 1 and school classes on Level 2. Our main models predicted the cross-sectional and longitudinal effects of ethnic victimization and different types of discrimination on students' health problems, while controlling for sex and age on Level 1, and class size and diversity on Level 2. Continuous predictors were z-standardized in order to facilitate the interpretation of regression coefficients. 


\section{Results}

\section{Descriptive Results}

Table 1 presents the descriptives and intercorrelations of ethnic victimization in school and different types of discrimination for all immigrant students. As expected, the average scores are in general low when considering the means across all students. When contrasting the means of each discrimination indicator across the three different countries, we reveal small average effect sizes (victimization in school: $d=.12$; discrimination in public transportation: $d=.10$; discrimination in leisure services: $d=.08$; discrimination by police or security personnel: $d=.16$ ), indicating small to negligible country differences. Despite the consistently low frequencies, however, these means still differ significantly from the minimum value, indicating that immigrant minority students perceive a small but not unimportant amount of ethnic victimization and discrimination. This conclusion is supported by the number of immigrant minority students who report experiencing - independently of its frequency - any discrimination, which ranges between $12 \%$ and $21 \%$. Moreover, the lower part of Table 1 reports low to moderate intercorrelations, suggesting that self-reported ethnic victimization and discrimination are not consistently directed towards the same individuals, but seem to target different immigrant group members across different settings and occasions. Besides the frequency of different types of discrimination, immigrant students reported having, on average, moderately high health problems at wave 1 ( $M$ $=2.51, S D=0.84)$ and wave $2(M=2.56, S D=0.86)$. Again, these means hardly differ across the different countries with an average effect size of $d=.08$ for wave 1 and $d=.05$ for wave 2 .

\section{Insert Table 1 about here}

Contrasting the frequency of all directly comparable types of discrimination reveals that discrimination by the police and security is experienced more often than discrimination in public transportation $(T(4333)=11.76, p<.001, d=.21)$ or discrimination in leisure services $(T(4333)$ $=10.59, p<.001, d=.19)$. These differences can be replicated when using the aforementioned 
recoded dichotomous discrimination variables (i.e., no discrimination versus any discrimination). That is, discrimination by police and security was perceived more often by immigrant students in Europe than other types of discrimination and, notwithstanding the small average scores of discrimination, seems to be a relatively common problem.

\section{Effects of Different Types of Discrimination}

We tested cross-sectional and longitudinal effects of ethnic victimization and discrimination on health problems within a multilevel framework including immigrant minority students on Level 1 nested in ethnically diverse school classes on Level 2. The Unconditional Models (i.e., without any predictors) determined the variance proportion in the outcome variable across both levels and revealed an intraclass coefficient of 0.02 for the cross-sectional Model and of 0.03 for the longitudinal Model. This indicates that $2 \%$ and $3 \%$ of the variance in current and future health problems is attributable to the contextual level, which differs significantly from zero $\left(\chi^{2}(581)=712, p<.001\right.$ and $\chi^{2}(541)=636, p<.01$, respectively). Table 2 summarizes both Full Models that examined cross-sectional and longitudinal effects of all predictors.

\section{Insert Table 2 about here}

In line with our hypothesis, the cross-sectional Model revealed significant associations between all predictors and immigrant students' self-reported health problems, while controlling for sex, age, class size, and diversity, indicating that perceived ethnic victimization and different types of discrimination have a negative relationship with immigrant students' health. A comparison of the relative strength of all cross-sectional associations shows that perceived police and security discrimination has the most negative link with immigrant students' health problems, yielding a significantly stronger association than ethnic victimization in school $(T(8664)=2.98, p$ $<.01)$, perceived discrimination in public transportation $(T(8664)=3.36, p<.01)$, and perceived discrimination in leisure services $(T(8664)=3.51, p<.01)$.

These findings can largely be replicated in the longitudinal Model in that ethnic victimization in school and perceived discrimination by the police and security reveal significant 
long-term effects on immigrant students' health problems one year later, while controlling for the same variables as the cross-sectional Model as well as health problems at wave 1. Although police and security discrimination tends to have a stronger impact on future health problems than does ethnic victimization in school, the difference between the strength of both significant predictors does not reach the level of statistical significance $(T(6468)=0.72, p>.05)$, suggesting that ethnic victimization in school and perceived discrimination by the police and security have similarly detrimental consequences. This difference between the longitudinal and the cross-sectional results might be due to methodological reasons: First, there was a rather long time interval between the two measurement points of one year which makes it difficult to detect relationships between variables in general - in fact the longitudinal effects for all predictors were smaller than the cross-sectional effects. Second, health problems had a relatively high stability over time, which, again, makes it difficult to find significant other predictors that are able to explain remaining variance in the criterion while controlling for autoregressive effects.

Additional interactions between the different types of discrimination with sex on the individual level and diversity on the contextual level revealed no significant effects, apart from one exception out of 16 tested interactions (i.e., sex interaction with school victimization becomes significant for health at wave 1 in that boys are more negatively affected; $B=-.05, S E=$ $.02, p<.05)$. This post-hoc analysis indicates that the revealed effects of discrimination on health are robust and tend to exist both for male and female immigrant students, and in less and more diverse classes.

In sum, the present results demonstrate that immigrant minority students in Europe report experiencing on average low but considerable frequencies of ethnic victimization and discrimination. These prevalence rates are worrying given the demonstrated impact of victimization and discrimination on immigrant group members' health. A particular problem seems to be discrimination experienced by the police and security personnel, which represents the most common and most detrimental form of discrimination examined in this study. 


\section{Discussion}

The primary purpose of the present study was to study the frequency and influence of perceived discrimination in general and discrimination by the police and security specifically on immigrant minority students' health. We addressed this question using a European cross-national sample of 14 year olds from 580 ethnically mixed school classes. In line with previous research, cross-sectional as well as longitudinal results revealed that different types of discrimination and victimization negatively influence immigrant students' health. Moreover, our results reveal that perceived discrimination by the police and security, the most common form of discrimination experienced by the participants, has a particularly negative effect on health outcomes. Focusing on the specifics of the European context, we did not deliberately address examples of physical violence by police officers targeted at ethnic and racial minority members but, rather, focused on a more common form of oppression, namely discrimination by the police (and security personnel). Police discrimination - of course - is not limited to the European context and is also a major social issue in the US (e.g., Nadall, Davidoff, Allicock, Serpe, \& Erazo, 2017).

Generally speaking, the present paper replicates previous research showing that perceived discrimination negatively impacts health in immigrant minorities in general (e.g., Conklin, 2011) and adolescent immigrant minorities in particular (Coker et al., 2009). Having said that, we wish to stress that studying the relationship between perceptions of discrimination and adolescent members of immigrant minority groups is of special importance because adolescents undergo an important and vulnerable development stage and are especially prone to suffer from negative effects of discrimination on health (e.g., Brody et al., 2006). In fact, using data from the U.S. Adam et al. (2015) showed that perceived racial discrimination during adolescence had an influence on biomarkers of stress (i.e., diurnal cortisol slopes and average cortisol levels) 20 years later. In other words, perceptions of discrimination at age twelve positively predicted physiological indicators of chronic stress at age 32. This effect was especially pronounced in 
African-Americans (compared to Whites). This finding not only illustrates the importance of studying perceived discrimination in adolescence but also impressively demonstrates the existence of long-term consequences of discrimination with regard to health disparities between ethnic groups (see also Wong, Eccles, \& Sameroff, 2003).

Beyond replicating the link between perceived general discrimination and health, we showed that discrimination by police and security personnel is the strongest predictor for health outcomes and is associated with immigrant students' health even when controlling for other types of discrimination (ethnic victimization in the school context as well as discrimination in clubs and restaurants or public transportation) and a number of sociodemographic and contextual variables.

What are possible reasons for these especially negative effects of discrimination by the police and security? One aforementioned reason might be that, due to the legitimized power imbalance between police-security organizations and victims of police discrimination, confronting such types of discrimination is especially difficult. This, in turn, limits the course of action open to victims, affecting their feelings of control, and hindering their functional coping. Moreover, individuals are motivated to perceive the world as a just place (Lerner \& Montada, 1998) in which victims are responsible for their misfortune (Lerner \& Montada, 1988). Hence, it is likely that targets of police and security discrimination are blamed by third parties, which should lead to a manifestation of stress symptoms (Kaiser et al., 2006).

It is worth noting that discrimination by police and security against immigrant minorities in our European data is reported at rather low levels. According to our data, most police and security forces seem to properly manage the existing power imbalance. However, inappropriate behavior by such forces, whether it is subjectively perceived or whether it objectively occurs, is a matter of concern given the outlined reasons for and demonstrated effects of discrimination by such bodies on immigrant minority group members' health. Moreover, the perception of discrimination by the police and security personnel and its consequences might contribute to 
explaining why adolescents in general and adolescent ethnic and immigrant minorities specifically show less trust in the police (Hurst, 2007; Schuck, 2013). This again is likely to decrease minority group members' interest in joining the police and security firms, which further exacerbates the problem as these organizations become increasingly mono-ethnic, and do not hear a minority voice within their ranks.

\section{Limitations and Future Research Directions}

We acknowledge a number of limitations of our research. First of all, the research builds on secondary data. Therefore, some of the measures were not chosen with the present project in mind and are suboptimal (e.g., single-item measures for the different types of discrimination). Future studies could try to address the content of discrimination experiences and ask for concrete examples of discrimination. Specifically, this data set measured discrimination by police and security with a single item, thus we cannot disaggregate discrimination by the police (officials of the state) from discrimination by private security companies, whose officials occupy a less prominent public role, and whose personnel selection process is not as carefully controlled. Moreover, it would be interesting to additionally study the influence of discrimination (by the police and security) on objective health variables (i.e., physiological stress indicators; e.g., Brondolo et al., 2008). Furthermore, it is important to note that we cannot completely rule out that ethnic victimization in school has a comparable or stronger effect on health outcomes. Because health outcomes and outside school discrimination are both measured with questionnaire items they share more method variance than health outcomes and the social network nominations for ethnic victimization. Hence, we might have underestimated the strength of the relationship between ethnic victimization in the school and health. Most importantly, our research is, like most other research in this field, limited in that we were unable to objectively measure discrimination. Instead we had to rely on immigrant minority group members' selfreported experiences of discrimination. In line with previous studies it is likely that participants in 
our study underestimated the extent to which they are discriminated against (Barreto \& Ellemers, 2015).

These limitations are opposed by a number of strengths of our research. Notably, we used a large multinational and highly externally valid sample. Moreover, the results can be considered as reliable and valid because they could be replicated in a longitudinal sample while controlling for the hierarchical structure of the data and a number of control variables (including social network data).

\section{Practical and Political Implications}

There are three main implications that can be derived from our finding that a) discrimination by the police and security personnel is, compared with other types of discrimination, a frequent form of discrimination experienced among students from immigrant minority groups and b) perceived discrimination by the police and security personnel has a negative effect on immigrant students' health. First, racial profiling (see, e.g., Amnesty International, 2014) as well as legal preconditions for racial profiling should be minimized. Following up our argument that police discrimination is especially harmful because victims have limited options to react to this form of discrimination, it would also be important to introduce ombudsmen for discrimination by both official police officers and unofficial personnel employed by private security companies. Victims of discrimination would then have the opportunity to complain and could regain some control over the situation, while at the same time police and security forces would have a more accurate picture of perceived discrimination by immigrants and ethnic and immigrant minority group members.

Second, because in some European countries (e.g., Germany and the Netherlands) police officers do not wear name tags or labels they are not identifiable; to our knowledge security personnel are routinely anonymous. This anonymity could lead to more non-normative behavior from such officials (Zimbardo, 1970). Furthermore, specific complaints are difficult for targets of discrimination which makes it difficult for police officers to be sanctioned. For these reasons, 
both police officers and employees of private security firms should be bound to wear identification tags.

Third, some research hints at a substantial number of prejudiced police officers (Correll, Park, Judd, \& Wittenbrink, 2007; Leenen, 2005; Pratto, Sidanius, \& Levin, 2006). Therefore, comprehensive anti-racism and anti-prejudice education should be integrated into the basic training of all police officers (e.g., Charbonneau et al., 2017; Sim, Correll, \& Sadler, 2013; but see also Scott et al., 2017). Also, building on studies showing that positive contact between members of different social groups - for example at the workplace - generally and intergroup friendship especially reduces prejudice (Pettigrew \& Tropp, 2011) authorities should also try to increase the number of ethnic minority members on all levels in the police force. This contact may have a beneficial effect not only on attitudes towards ethnic minorities, but also on personality characteristics associated with prejudice, such as social dominance orientation (SDO). Sidanius, Liu, Pratto, and Shaw (1994) found that, compared to people working in the field of public defense, police officers in Los Angeles had higher average SDO scores, indicating that they were more favorable to maintaining hierarchical relations between groups. This tendency when entering the police force may be further enhanced by training and working in a 'hierarchy-enhancing' environment (i.e., one which enhances hierarchy and inequalities; Sidanius and Pratto, 1999), and the police are given as an example of an anti-egalitarian normative environment, because they facilitate the distribution of negative social resources regarding subordinate groups (De Oliviera, Guimond, \& Dambrun, 2012). Intergroup contact has been showen to reduce SDO scores (Dhont, Van Hiel, \& Hewstone, 2014). 
${ }^{1}$ The immigrant minority sample consists of individuals with diverse ethnic backgrounds. The background of our adolescent immigant minority samples in our study were in line with each country's largest immigrant groups (Germany: Turkish or former Soviet Union; Netherlands: Turkish, Moroccan, or Surinamese/Antillean; Sweden: Iraqi or former Yugoslavian). 


\section{References}

Adam, E. K., Heissel, J. A., Zeiders, K. H., Richeson, J. A., Ross, E. C., Ehrlich, K. B., ... Peck, S. C. (2015). Developmental histories of perceived racial discrimination and diurnal cortisol profiles in adulthood: A 20-year prospective study. Psychoneuroendocrinology, 62, 279-291. doi: 10.1016/j.psyneuen.2015.08.018

Amnesty International. (2014). Racial/Ethnic Profiling: Position von Amnesty International zu menschenrechtswidrigen Personenkontrollen [Racial/Ethnic Profiling: Amnesty International's

Position on Degrading Identity Checks]. Retrieved from https://www.amnesty.de/files/Racial_Profiling_Positionspapier_Kurzfassung_September_201 4.pdf

Amnesty International USA. (2015). Deadly Force - Police Use of Lethal Force in the United States.

Retrieved from https://www.amnestyusa.org/sites/default/files/aiusa_deadlyforcereportjune2015.pdf

Barreto, M., \& Ellemers, N. (2015). Advances in Experimental Social Psychology, 52, 139-219. doi: 10.1016/bs.aesp.2015.02.001

Benner, A. D., \& Kim, S. Y. (2009). Experiences of discrimination among Chinese American adolescents and the consequences for socioemotional and academic development. Developmental Psychology, 45(6), 1682-1694. doi: 10.1037/a0016119

Bennett, G. G., Wolin, K. Y., Robinson, E. L., Fowler, S., \& Edwards, C. L. (2005). Racial/ethnic harassment and tobacco use among African American young adults. American Journal of Public Health, 95(2), 238-240. doi: 10.2105/AJPH.2004.037812

Berg, A. O., Melle, I., Rossberg, J. I., Romm, K. L., Larsson, S., Lagerberg, T. V., ... Hauff, E. (2011). Perceived discrimination is associated with severity of positive and depression/anxiety symptoms in immigrants with psychosis: A cross-sectional study. BMC Psychiatry, 11(77). doi: 10.1186/1471-244X-11-77 
Bergman, L. R., \& Magnusson, D. (1997). A person-oriented approach in research on developmental psycho-pathology. Development and Psychopathology, 9(2), 291-319. doi: 10.1017/S095457949700206X

Bonino, S. (2015). Visible Muslimness in Scotland: between discrimination and integration. Patterns of Prejudice, 49(4), 367-391. doi: 10.1080/0031322X.2015.1066978

Borders, A., \& Liang, C. T. H. (2011). Rumination partially mediates the associations between perceived ethnic discrimination, emotional distress, and aggression. Cultural Diversity and Ethnic Minority Psychology, 17(2), 125-133. doi: 10.1037/a0023357

Brody, G. H., Chen, Y. F., Murry, V. M., Ge, X., Simons, R. L., Gibbons, F. X., ... Cutrona, C. E. (2006). Perceived discrimination and the adjustment of African American youths: A five-year longitudinal analysis with contextual moderation effects. Child Development, 77(5), 1170-1189. doi: $0.1111 / \mathrm{j} .1467-8624.2006 .00927 . x$

Brondolo, E., Libby, D. J., Denton, E., Thompson, S., Beatty, D. L., Schwartz, J., ... Gerin, W. (2008). Racism and ambulatory blood pressure in a community sample. Psychosomatic Medicine, 70(1), 49-56. doi: 10.1097/PSY.0b013e31815ff3bd

Bundespolizeigesetz [German police law], \22 (1994).

Byrant-Davis, T., Adams, Tyronna, Alejandre, A., \& Gray, A. A. (2017). The trauma lens of police violence against racial and ethnic minorities. Journal of Social Issues, 73(4).

Cairns, R. B., Cairns, B. D., \& Neckerman, H. J. (1989). Early school dropout: Configurations and determinants. Child Development, 60(6), 1437-1452. doi: 10.2307/1130933

Carter, R. T. (2007). Racism and psychological and emotional injury: recognizing and assessing race-based traumatic stress. The Counseling Psychiatrist, 35(1), 13-105. doi: $10.1177 / 0011000006292033$

Charbonneau, A., Spencer, K., \& Glaser, J. (2017). Understanding racial disparities in police use of lethal force: Lessons from fatal police-on-police shootings. Journal of Social Issues, 73(4). 
CILS4EU (2014). Children of Immigrants Longitudinal Survey in Four European Countries. Codebook. Wave 1 - 2010/2011, v1.1.0. Mannheim: Mannheim University.

CILS4EU (2014). Children of Immigrants Longitudinal Survey in Four European Countries. Technical report. Wave 1 - 2010/2011, v1.1.0. Mannheim: Mannheim University.

CILS4EU (2015). Children of Immigrants Longitudinal Survey in Four European Countries. Codebook. Wave 2 - 2011/2012, v2.0.0. Mannheim: Mannheim University.

Correll, J., Park, B., Judd, C. M., \& Wittenbrink, B. (2002). The police officer's dilemma: using ethnicity to disambiguate potentially threatening individuals. Journal of Personality and Social Psychology, 83(6), 1314-1329. doi: 10.1037//0022-3514.83.6.1314

Coker, T. R., Elliott, M. N., Kanouse, D. E., Grunbaum, J. A., Schwebel, D. C., Gilliland, M. J., \& Schuster, M. A. (2009). Perceived racial/ ethnic discrimination among fifth-grade students and its association with mental health. American Journal of Public Health, 99(5), 878-884. doi: 10.2105/AJPH.2008.144329

Conklin, H. D. (2011). Perceived Racism and Mental Health: A Meta-Analytic Review (Doctoral dissertation). Retrieved from http://scholarsarchive.byu.edu/cgi/viewcontent.cgi?article=4034.

De Oliviera, P., Guimond, S., \& Dambrun, M. (2012). Power and legitimizing ideologies in hierarchy-enhancing vs. hierarchy-attenuating environments. Political Psychology, 33, 867-885.

Dhont, K., Van Hiel, A., \& Hewstone, M. (2014). Changing the ideological roots of prejudice: Longitudinal effects of ethnic intergroup contact on social dominance orientation. Group Processes \& Intergroup Relations, 17, 27-44.

Dijkstra, J., Lindenberg, S., Veenstra, R., Steglich, C., Isaacs, J., Card, N. A., \& Hodges, E. V. E. (2010). Influence and selection processes in weapon carrying during adolescence: The roles of status, aggression, and vulnerability. Criminology, 48(1), 187-220. doi: 10.1111/j.17459125.2010.00183.x 
Dodd, E. H., Giuliano, T. A., Boutell, J. M., \& Moran, B. E. (2001). Respected or rejected: Perceptions of women who confront sexist remarks. Sex Roles, 45, 567-577. doi: 10.1023/A:1014866915741

Dollase, R. (2000). Wer kontrolliert die Qualität polizeilicher Arbeit? In Empirische Polizeiforschung: Interdisziplinäre Perspektiven in einem sich entwickelnden Forschungsfeld. [Who controls the quality of police work? In K. Liebel and T. Ohlemacher (Eds.), Empirische Polizeiforschung: Interdisziplinäre Perspektiven in einem sich entwickelnden Forschungsfeld. [Empirical police research: Interdisciplinary perspectives in a developed research field] (pp. 132-142). Herbolzheim: Centaurus Verlagsgesellschaft.

European Union Agency for Fundamental Rights. (2010). European Union Minorities and Discrimination Survey. Retrieved from http://fra.europa.eu/sites/default/files/fra_uploads/1132-EU-MIDIS-police.pdf

Fisher, C. B., Wallace, S. A., \& Fenton, R. E. (2000). Discrimination distress during adolescence. Journal of Youth and Adolescence, 29(6), 679-695. doi: 10.1023/A:1026455906512

Gabbidon, S. L. (2003). Racial Profiling by Store Clerks and Security Personnel in Retail Establishments. An Exploration of "Shopping While Black". Journal of Contemporary Criminal Justice, 19(3), 345-364. doi: 10.1177/1043986203254531

Gee, G. C., Spencer, M., Chen, J., \& Takeuchi, D. (2007). A nationwide study of discrimination and chronic health conditions among Asian Americans. American Journal of Public Health, 97(7), 1275-1282. doi: 10.2105/AJPH.2006.091827

Gee, G. C., Ryan, A., Laflamme, D. J., \& Holt, J. (2006). Self-reported discrimination and mental health status among African descendants, Mexican Americans, and other Latinos in the New Hampshire REACH 2010 initiative: The added dimension of immigration. American Journal of Public Health, 96(10), 1821-1828. doi: 10.2105/AJPH.2005.080085

Greene, M. L., Way, N., \& Pahl, K. (2006). Trajectories of perceived adult and peer discrimination among Black, Latino, and Asian American adolescents: Patterns and 
psychological correlates. Developmental Psychology, 42(2), 218-236. doi: 10.1037/00121649.42.2.218

Haberfeld, M. (2013). Critical issues in police training (2 ${ }^{\text {nd }}$ Edition). New York (NY): Pearson Learning Solutions.

Hirschfield, P. J. (2015a). Why American cops kill so many compared to European cops. The Huffington Post. Retrieved from http://www.huffingtonpost.com/entry/american-copslethal_us_565cde59e4b079b2818b8870

Hirschfield, P. J. (2015b, November, 11). Lethal policing: Making sense of American exceptionalism. Sociological Forum, 30(4), 1109-1117. doi: 10.1111/socf.12200

Hurst, Y. G. (2007). Juvenile attitudes toward the police - An examination of rural youth. Criminal Justice Review, 32(2), 121-141. doi: 10.1177/0734016807300141

Huynh, V. W., \& Fuligni, A. J. (2010). Discrimination hurts: The academic, psychological, and physical well-being of adolescents. Journal of Research on Adolescence, 20(4), 916-941. doi:10.1111/j.1532-7795.2010.00670.x

Hyers, L. L. (2007). Resisting prejudice every day: Exploring women's assertive responses to antiblack racism, anti-semitism, heterosexism, and sexism. Sex Roles, 56(1), 1-12. doi: $10.1007 /$ s11199-006-9142-8

Inzlicht, M., McKay, L., \& Aronson, J. (2006). Stigma as ego depletion: How being the target of prejudice affects self-control. Psychological Science, 17(3), 262-269. doi: 10.1111/j.14679280.2006.01695.x

Jasinskaja-Lahti, I. , Liebkind, K., Jaakkola, M., \& Reuter, A. (2006). Perceived discrimination, social support networks and psychological well-being among three immigrant groups. Journal of Cross-Cultural Psychology, 37(3), 293-311. doi: 10.1177/0022022106286925

Kaiser, C. R., \& Major, B. (2006). A social psychological perspective on perceiving and reporting discrimination. Law and Social Inquiry, 31(4), 801-830. doi: 10.1111/j.1747-4469.2006.00036.x 
Kaiser, C. R., Dyrenforth, P. S., \& Hagiwara, N. (2006). Why are attributions to discrimination interpersonally costly? A test of system- and group-justifying motivations. Personality and Social Pschology Bulletin, 32(11), 1523-1536. doi: 10.1177/0146167206291475

Kahn, K. B., \& Davies, P. G. (2017) What influences shooter bias? The effects of suspect race, neighborhood, and clothing on decisions to shoot. Journal of Social Issues, 73(4).

Kalter, F., Heath, A. F., Hewstone, M., Jonsson, J. O., Kalmijn, M., Kogan, I., \& van Tubergen, F. (2014). Children of Immigrants Longitudinal Survey in Four European Countries (CILS4EU) - Full version. Data file for on-site use. GESIS Data Archive, Cologne, ZA5353.

KOP Berlin (2014, 20 October). Racial Profiling: Zwischenbericht der Initiative Schwarze Menschen in Deutschland (ISD) und der Kampagne für Opfer rassistischer Polizeigewalt (KOP) zur Verhandlung des Falls von Kläger Derege Wevelsiep am 30. Oktober in Frankfurt/Main [Racial Profiling: Intermediate report of the Initiative Black people in Germany and Campaign for the victims of racist police violence regarding the trial of Derege Wevelsiep at October 20 in Frankfurt/Main] [Web log message]. Retrieved from https://www.kopberlin.de/beitrag/racial-profiling-zwischenbericht-der-initiative-schwarze-menschen-indeutschland-isd-und-der-kampagne-fur-opfer-rassistischer-polizeigewalt-kop-zur-verhandlungdes-falls-von-klager-derege-wevelsiep-am-30-oktober-in-frankfurt-main.

Landrine, H., \& Klonoff, E. A. (1996). The Schedule of Racist Events: A measure of racial discrimination and a study of its negative physical and mental health consequences. Journal of Black Psychology, 22, 144-168. doi: 10.1177/00957984960222002

Lartey, J. (2015). By the numbers: US police kill more in days than other countries do in years. The Guardian. Retrieved from http://www.theguardian.com/us-news/2015/jun/09/thecounted-police-killings-us-vs-other-countries

Leenen, W. R. (2005). Ausländerfeindlichkeit als Ausgangspunkt einer interkulturellen Qualifizierungsstrategie für die Polize?? [Xenophobia as a starting point of an intercultural training strategy for the police?] In W. R. Leenen, H. Grosch \& A. Groß, Bausteine zur interkulturellen 
Qualifizierung der Polizei [Modules for police intercultural training] (pp. 15-39). Münster: Waxmann.

Lerner, M. J., \& Montada, L. (1998). An overview: Advances in belief in a just world theory and methods. In L. Montada \& M. J. Lerner (Eds.). Responses to Victimizations and Belief in a Just World. Plenum Press: New York.

Major, B., Quinton, W. J., \& McCoy, S. K. (2002). Antecedents and consequences of attributions to discrimination: Theoretical and empirical advances. In M. P. Zanna (Ed.), Advances in experimental social psychology (Vol. 34, pp. 251-330). San Diego, CA: Academic Press.

Mewes, R., Asbrock, F., \& Laskawi, J. (2015). Perceived discrimination and impaired mental health in Turkish immigrants and their descendents in Germany. Comprehensive Psychiatry, 62, 4250, doi: 10.1016/j.comppsych.2015.06.009

Migrant Integration Policy Index. (2015). Available from http://www.mipex.eu

Mletzko, M. \& Cornelia, W. (1999). Polizei und Fremdenfeindlichkeit. [Police and hostility toward strangers]. Monatsschrift für Kriminologie und Strafrechtsreform, 82, 77-93.

Nadall, K. L., Davidoff, K., Allicock, N., Serpe, C., \& Erazo, T. (2017). Perceptions of police, racial profiling, and psychological outcomes: A mixed methodological study. Journal of Social Issues, 73(4).

Okazaki, S. (2009). Impact of Racism on Ethnic Minority Mental Health. Perspectives on Psychological Science, 4(1), 103-107. doi: 10.1111/j.1745-6924.2009.01099

Pascoe, E. A., \& Smart Richman, L. (2009). Perceived discrimination and health: A meta-analytic review. Psychological Bulletin, 135(4), 531-554. doi: 10.1037/a0016059

Pratto, F., Sidanius, J., \& Levin, S. (2006). Social dominance theory and the dynamics of intergroup relations: Taking stock and looking forward. European Review of Social Psychology, 17(1), 271-320. doi: 10.1080/10463280601055772

Raudenbush, S. W., \& Bryk, A. S. (2002). Hierarchical linear models: Applications and data analysis methods (2nd ed.). Thousand Oaks, CA: Sage. 
Reicher, S., \& Stott, C. (2011). Mad mobs and Englishmen: Myths and realities of the 2011 riots. New York: Constable \& Robinson.

Sim, J. J., Correll, J. \& Sadler, M. S. (2013). Understanding police and expert performance: When training attenuates (vs. Exacerbates) stereotypic bias in the decision to shoot. Personality and Social Psychology Bulletin, 39, 291-304. doi: 10.1177/0146167212473157

Schmitt, M. T., Branscombe, N. R., Postmes, T., \& Garcia, A. (2014). The consequences of perceived discrimination for psychological well-being: A meta-analytic review. Psychological Bulletin, 140(4), 921-948. doi: 10.1037/a0035754

Schuck, A. M. (2013). A life-course perspective on adolescents' attitudes to police - DARE, delinquency, and residential segregation. Journal of Research in Crime and Delinquency, 50(4), 579607. doi: $10.1177 / 0022427813481977$

Scott, K., Correll, J., Sadler, M. S., \& Ma, S. D. (2017). A social scientific approach toward understanding racial disparities in police shooting: Data from the Department of Justice (19802000). Journal of Social Issues, 73(4).

Seaton, E. K., Caldwell, C. H., Sellers, R. M., \& Jackson, J. S. (2010). An intersectional approach for understanding perceived discrimination and psychological well-being among African American and Caribbean Black youth. Developmental Psychology, 46(5), 1372-1379. doi: $10.1037 / \mathrm{a} 0019869$

Seligman, M. E. P. (1975). Helplessness. On Depression, Development and Death. San Francisco: Freeman and Comp.

Sharp, D., \& Atherton, S. (2007). To serve and protect? The experiences of policing in the community of young people from Black and other ethnic minority groups. British Journal of Criminology, 47(5), 746-763. doi: 10.1093/bjc/azm024

Sidanius, J., Liu, J., Pratto, F., \& Shaw, J. (1994). Social dominance orientation, hierarchy attenuators and hierarchy enhancers: Social dominance theory and the criminal justice system. Journal of Applied Social Psychology, 24, 338-366. 
Sidanius, J., \& Pratto, F. (1999). Social dominance: An intergroup theory of social bierarchy and oppression. New York, NY: Cambridge University Press.

Sorenson, S. B., \& Vittes. K. A. (2004). Adolescents and Firearms: A California Statewide Survey. American Journal of Public Health, 94(5), 852-858. doi: 10.2105/AJPH.94.5.852

Steele, C. M., \& Aronson, J. (1995). Stereotype threat and the intellectual test performance of African Americans. Journal of Personality and Social Psychology, 69(5), 797-811. doi: 10.1037//00223514.69.5.797

Sue, D. W., Capodilupo, C. M., Torino, G. C., Bucceri, J. M., Holder, A., Nadal, K. L., \& Esquilin, M. (2007). Racial microaggressions in everyday life: implications for clinical practice. American Psychologist, 62(4), 271-286. doi: 10.1037/0003-066X.62.4.271

Van Craen, M., \& Skogan, W. G. (2015). Differences and similarities in the explanation of ethnic minority groups' trust in the police. European Journal of Criminology, 12(3), 300-323. doi: $10.1177 / 1477370814535375$

Van Craen, M. (2013). Explaining majority and minority trust in the police. Justice Quarterly, 30(6), 1042-1067. doi: 10.1080/07418825.2011.649295

Verkuyten, M. (2008). Life satisfaction among ethnic minorities: The role of discrimination and group identification. Social Indicators Research, 89(3), 391-404. doi: 10.1007/s11205-008-9239-2

Verkuyten, M., \& Nekuee, S. (1999). Subjective well-being, discrimination and cultural conflict: Iranians living in the Netherlands. Social Indicators Research, 47(3), 281-306. doi: 10.1023/A:1006970410593

Viruell-Fuentes, E. A., Miranda, P.Y., \& Abdulrahim, S. (2012). More than culture: Structural racism, intersectionality theory, and immigrant health. Social Science \& Medicine, 75(12), 20992106. doi: 10.1016/j.socscimed.2011.12.037

White, A. (2011). The new political economy of private security. Theoretical Criminology, 16(1), 85101. doi: $0.1177 / 1362480611410903$ 
Williams, D. R., \& Mohammed, S. A. (2013). Racism and health I: pathways and scientific evidence. American Behavioral Scientist, 57(8), 1152-1173. doi: 10.1177/0002764213487340

Wölfer, R., \& Hewstone, M. (2015). Intra- versus intersex aggression: Testing theories of sex differences using aggression networks. Psychological Science, 26(8), 1285-1294. doi: $10.1177 / 0956797615586979$

Wong, C. A., Eccles, J. S., \& Sameroff, A. (2003). The influence of ethnic discrimination and ethnic Identification on African American adolescents' school and socioemotional adjustment. Journal of Personality, 71(6), 1197-1232. doi: 10.1111/1467-6494.7106012

Zick, A., Pettigrew, T. F., \& Wagner, U. (2008). Ethnic prejudice and discrimination in Europe. Journal of Social Issues, 64(2), 233-251. doi: 10.1111/j.1540-4560.2008.00559.x 


\section{Tables}

Table 1. Frequency of Perceived Victimization and Discrimination by Minority Students

\begin{tabular}{|c|c|c|c|c|}
\hline & 1 Ethnic & 2 Discrimination & 3 Discrimination & 4 Discrimination \\
\hline & Victimization in & in Public & in Leisure & by Police or \\
\hline & School Class & Transportation & Services & Security \\
\hline & & & & Personnel \\
\hline Means $^{1}$ & $0.32(.72)$ & $1.14(.41)$ & $1.15(0.42)$ & $1.25(.64)$ \\
\hline Minimum & 0 & 1 & 1 & 1 \\
\hline Maximum & 5 & 4 & 4 & 4 \\
\hline$\Delta$ from minimum $^{2}$ & $T=29.05^{* * *}$ & $T=22.00 * * *$ & $T=23.66^{* * *}$ & $T=26.23^{* * *}$ \\
\hline$n>$ minimum $^{2}$ & $21 \%$ & $12 \%$ & $13 \%$ & $17 \%$ \\
\hline 2 & $.08^{* * *}$ & & & \\
\hline 3 & $.05^{* *}$ & $.50 * * *$ & & \\
\hline 4 & .01 & $.29 * * *$ & $.35^{* * *}$ & \\
\hline
\end{tabular}

Note. ${ }^{1}$ Standard deviations are shown in respective parentheses; ${ }^{2}$ The minimum value is 0 for the victimization score. Scaling for the discrimination item ranges from 1 (never) to 4 (always). ${ }^{* *} p<0.01,{ }^{* * *} p<0.001$ 
Table 2. Multilevel Prediction of Minority Students' Health Problems

\begin{tabular}{|c|c|c|c|c|c|c|}
\hline & \multicolumn{3}{|c|}{ Cross-sectional Effects } & \multicolumn{3}{|c|}{ Longitudinal Effects } \\
\hline & $B$ & $p$ & SE & $B$ & $p$ & SE \\
\hline \multicolumn{7}{|l|}{ Level 1: Students } \\
\hline Victimization in School & .045 & $* * *$ & .012 & .029 & $* *$ & .012 \\
\hline PD in Public Transportation & .031 & $*$ & .015 & .002 & & .017 \\
\hline PD in Leisure Services & .028 & $*$ & .015 & -.005 & & .017 \\
\hline PD by Police or Security & .100 & $* * *$ & .014 & .044 & $* *$ & .017 \\
\hline Health Problems wave 1 & & & & .546 & $* * *$ & .018 \\
\hline \multicolumn{7}{|l|}{ Level 2: School Classes } \\
\hline Class Size & -.028 & * & .013 & -.018 & & .013 \\
\hline Diversity & -.012 & & .013 & .010 & & .014 \\
\hline \multicolumn{7}{|l|}{ Unconditional Model } \\
\hline L1-Variance $(R)$ & & 0.692 & & & 0.734 & \\
\hline L2-Variance $\left(U_{0}\right)$ & & 0.013 & & & 0.019 & \\
\hline \multicolumn{7}{|l|}{ Final Model } \\
\hline L1-Variance $(R)$ & & 0.622 & & & 0.483 & \\
\hline $\mathrm{L} 2-$ Variance $\left(U_{0}\right)$ & & 0.004 & & & 0.017 & \\
\hline
\end{tabular}

Note. PD denotes perceived discrimination. All models control for sex and age;

one-tailed significance, ${ }^{*} p<.05,{ }^{* *} p<.01,{ }^{* * *} p<.001$. 
Figures

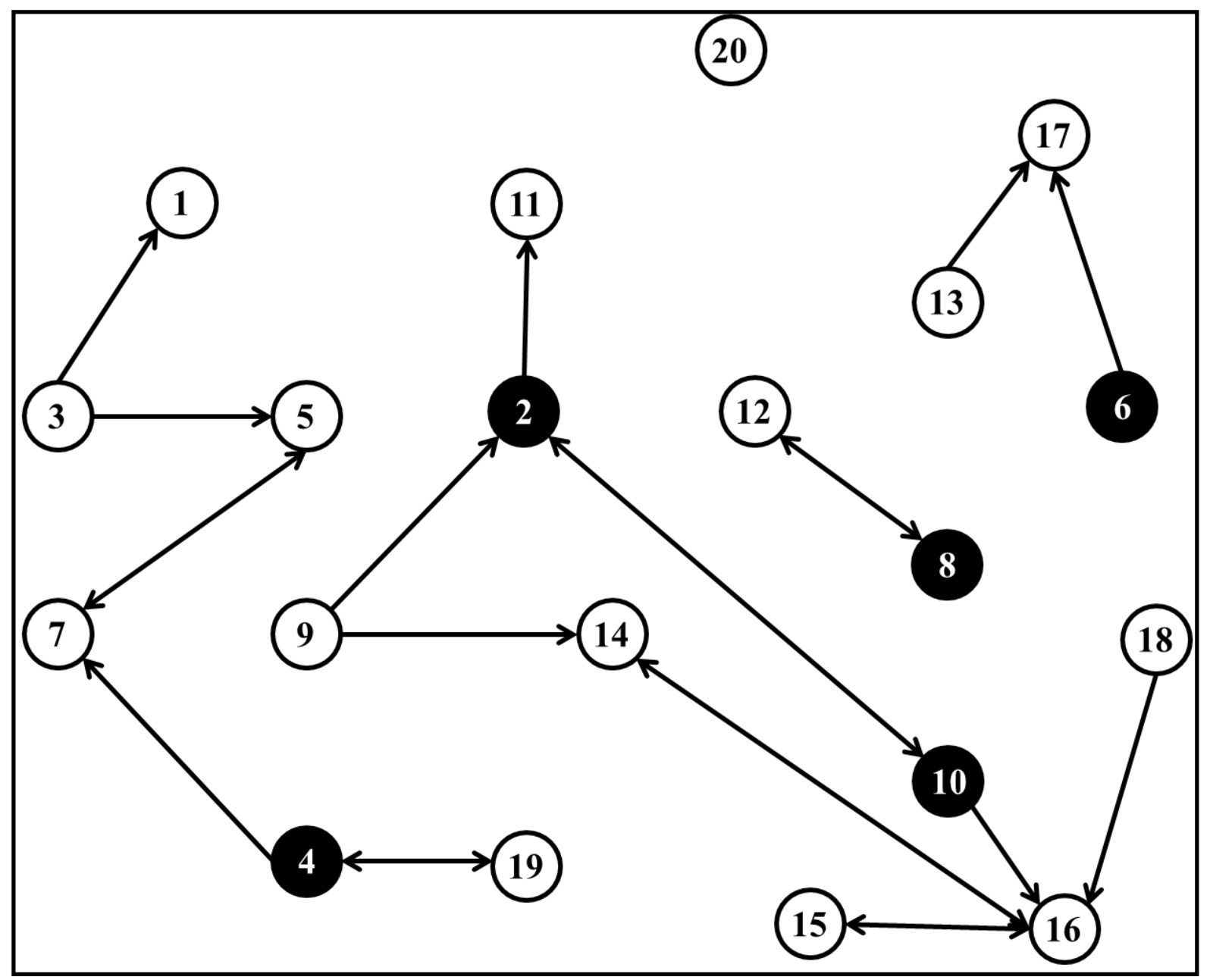

Figure 1. Sample negative network of a class that structures students (colored by ethnicity: White

$=$ majority, Black $=$ minority) using negative network ties while arrows indicate the nominated aggressor. 